\title{
Gravity inversion modeling across a 2-D dike-like structure-A Case Study
}

\author{
I. L. Ateya and Shuzo Takemoto \\ Department of Geophysics, Kyoto University, Kitashirakawa Oiwake-cho, Sakyo-ku, Kyoto City, Kyoto 606-8502, Japan
}

(Received January 17, 2002; Revised May 13, 2002; Accepted June 4, 2002)

\begin{abstract}
Gravity investigations do have certain known limitations, the two most prominent perhaps being deep resolution and the non-uniqueness of the solution. We utilized the principle of the physical geometry a two-dimensional dike in the inversion process across tectonic line in the Chubu District, Honshu-in the Japan Alps. The location is probably where the Tsunan-Matsumoto tectonic line interacts with the Itoigawa-Shizuoka Tectonic Line (ISTL). Two-dimensional modeling results consistent with previous works on gravity and reflection and/or refraction prospecting are given to depict the probable sub-surface structure. We conclude that the Bouguer gravity anomaly low to the Southwest or Western side of the tectonic trace is due to thrust of lower density sedimentary rocks deeper into the higher density lower crust to a depth range of approximately $3.5 \sim 4.0 \mathrm{~km}$ below the Earth surface.
\end{abstract}

\section{Introduction}

One of the most common problems encountered in geophysical studies is how to determine the geometry of the geological contacts at depth since every geologic province has unique geometric and/or physical parameters. Generally, geophysical modeling is addressed in terms of depth to simple-shaped sources or depth to geometric interfaces that represent geological contacts. This approach has led to a variety of different inversion techniques that are all subject to the well-known non-uniqueness of potential-fields causative sources.

The difficulties faced on seeking an inverse solution are primarily due to (i) the observed data belonging to real Earth whereas computed data belongs to a contrived Earth model, (ii) the discrete nature of data and therefore practically of a limited set and (iii) the presence of errors introduced by the measuring system, leading to the characteristic solution of inconsistency, non-uniqueness and instability. The other possible sources for ambiguity are (i) sub-surface features that are not adequately characterized by a two-dimensional (2-D) polygonal model (ii) influence of inadequate terrain correction and/or near-surface heterogeneities and (iii) superposition of closely spaced distinct sub-surface features (Butler, 1995). However, Parasnis (1997) maintains that in most practical situations a gravity interpretation can be approached usefully with some external control (e.g. geological information, drill hole data, etc.).

In this paper, we present sub-surface interpretation method to identify dike(s) from gravity data that utilizes two types of constraints. To establish an inequality constraint, geological information about the rock types or about the expected lower or upper bounds of the source depth and extent can be used (e.g. Parker, 1974). Further, the absolute proximity constraint when combined with other stabilizing constraints,

Copy right(C) The Society of Geomagnetism and Earth, Planetary and Space Sciences (SGEPSS); The Seismological Society of Japan; The Volcanological Society of Japan; The Geodetic Society of Japan; The Japanese Society for Planetary Sciences. allows the incorporation of geologic information e.g. from boreholes, surface mapping (e.g. Medeiros and Silva, 1996; Barbosa et al., 1997). We utilize inequality and absolute proximity constraints in that the rocks density contrasts and depths to rock types lies within certain specified limits obtained from available geological and/or geophysical data. We applied the method to a gravity anomaly profile across Itoigawa-Shizuoka Tectonic Line (ISTL) at Latitude 36.30 degrees North to depict the possible sub-surface structure.

\section{Methodology}

A given gravity signal is a convolution of the gravity effect of the source's density distribution with the effect of its geometry (depth, size) and distance from plane of observation (Blakely, 1996). Assuming a uniform or variable density contrast in the sub-surface, it is possible to calculate from the signal the probable geometry and/or interpretation parameters of the sub-surface causative structure.

\subsection{Variable density contrast}

The densities of sedimentary rocks often vary with the horizontal and depth location because of the effects of stratigraphic layering, facies variations, diagenesis, tectonic history, cementations and compaction from geostatic pressure. Thus, variable density contrasts rather than constant density contrasts should be considered in the interpretation subsurface structures. The variation in the density contrasts with depth can be approximated by a smooth function either quadratic or exponential by least squares fitting of the function to the observed data (Rao, 1986; Zhang et al., 2001). Zhang et al. (2001) gives gravity anomalies of 2-D bodies with layers of variable density contrast like rectangular cylinders and inclined fault models. Following method after Rao (1986) and Zhang et al. (2001), we approximated the variable density contrast in the sub-surface based on geological data in the vicinity of the tectonic line as $\Delta \rho(z)=$ $-0.515+0.109 z-0.003 z^{2} \mathrm{~g} / \mathrm{cm}^{3}$. Table 1 shows the various rock types, densities and approximate depths used to 
Table 1. Densities of various rock types utilized in the inversion modeling process. Sources: *Hirokawa (1978), ${ }^{+}$Telford et al. (1990) and ${ }^{++}$Burger (1992).

\begin{tabular}{lccc}
\hline \multicolumn{1}{c}{ Rock types } & Range $\left(\mathrm{g} / \mathrm{cm}^{3}\right)$ & Model Density $\left(\mathrm{g} / \mathrm{cm}^{3}\right)$ & Depth $(\mathrm{km})$ \\
\hline Alluvial Deposits* & $2.00-2.25$ & 2.12 & $<0.3$ \\
Fluvial Deposits (5 Ma)* $^{*}$ & $1.95-2.30$ & 2.25 & $<0.4$ \\
Turbidites (Miocene) $^{*}$ & - & 2.54 & $<2.0$ \\
Sedimentary Rocks* & $2.30-2.70$ & 2.60 & $1.7-5.0$ \\
Igneous Rocks (Basalt) $^{+}$ & $2.70-3.30$ & 2.99 & - \\
Metamorphic Rocks $^{++}$ & $2.6-3.10$ & 2.74 & - \\
Igneous Rocks (Granite) $^{+}$ & $2.50-2.81$ & 2.64 & $>5.00$ \\
Earth Crust* $^{*}$ & $3.27 \sim$ & 3.27 & - \\
\hline
\end{tabular}

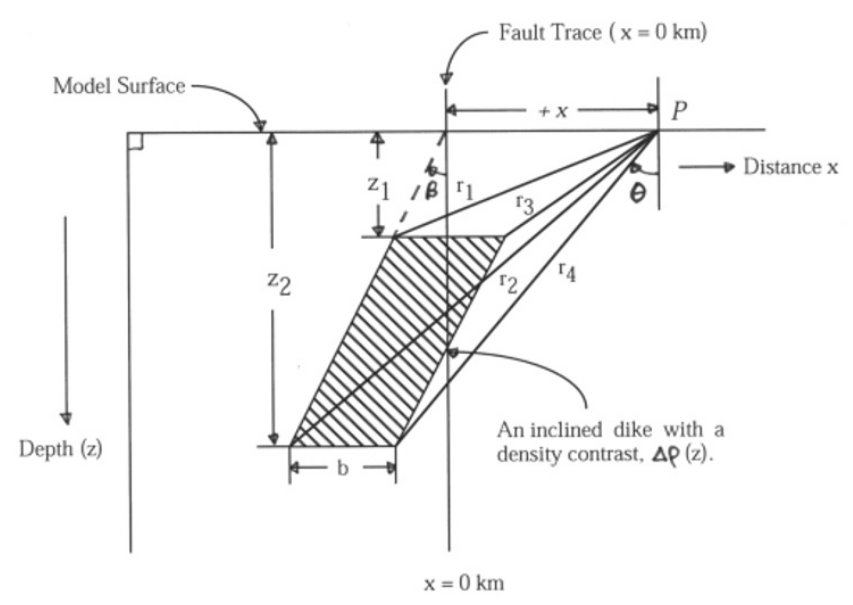

Fig. 1. Model diagram with the parameters and/or variables describing the gravity (anomaly) effect of two-dimensional sub-surface dike.

estimate the density contrasts function, $\Delta \rho(z)$.

\subsection{Two-dimensional dike model}

For simplicity we assume gravity data interpolated onto a regular grid and the top surface of the model is coincident to reference level, $z_{0}$. The gravity anomaly effect at a surface station $P$ is dependent on the geometry and/or parameters of the sub-surface dike as shown in Fig. 1. The surface gravity anomaly effect $g_{i}$ a 2-D dike obtained by the subtraction of two slabs one being displaced horizontally with respect to the other can be given by (Geldart et al., 1966; Telford et al., 1990):

$g_{i}=2 G * \Delta \rho *\left[\cos ^{2} \beta\left\{x_{i}\left(F_{2}-F_{1}\right)-\left(x_{i}-b\right)\left(F_{4}-F_{3}\right)\right\}\right]$

where $G$ is the universal gravitational constant $\Delta \rho$ the density contrast of the sub-surface dike for $i=1,2, \ldots, N$ (tectonic trace lies at $x=0$ ). The functions $F_{k}$ where $k=1,2, \ldots$ are defined by the relations

$$
F_{k}=\psi_{k} \cot \psi_{k}^{\prime}-\ln \left(\sin \psi_{k}\right) \quad \text { and } \quad x_{i} / \sin \psi_{k}=r_{k} / \cos \beta
$$

whereby $\psi_{k}^{\prime}=\theta_{k}-\beta, \tan \theta_{k}=\tan \beta+x_{i} / z_{k} ; z_{1}$ and $z_{2}$ are the depth to the top and bottom of the block respectively. In the dike model the distance $x_{i}$ is positive when the point $P$ is to the right of the tectonic trace with angles $\beta$ and $\theta_{k}$ being measured from the vertical while $\psi_{k}^{\prime}$ is measured from the fault plane.

\subsection{The inverse problem}

Let $\mathbf{p}$ be the $M$-dimensional vector whose elements $p_{j}$ are the geometrical parameters of the dike to be estimated by $\mathbf{p} \equiv\left\{p_{1}, p_{2}, \ldots, p_{M}\right\}^{T}$ and $\mathbf{g} \equiv \mathbf{g}(\mathbf{p}) \equiv\left\{g_{1}, g_{2}, \ldots, g_{N}\right\}^{T}$ be the $N$-dimensional vector whose $i$ th element $g_{i}$ is the computed gravity anomaly at the $i$ th observation point. Estimating $\mathbf{p}$ (the parameters of sub-surface interpretation) from $\mathbf{g}$ is an ill-posed nonlinear inverse problem formulated as the minimization of the functional $\phi^{g}$ given by:

$$
\phi^{g}\left(\mathbf{g}, \mathbf{g}^{0}\right)=\left(\left\|\mathbf{g}-\mathbf{g}^{0}\right\|^{2}\right) / M
$$

where $\|\cdot\|$ is the Euclidean norm and $\mathbf{g}^{0} \equiv\left\{g_{1}^{0}, g_{2}^{0}, \ldots, g_{N}^{0}\right\}^{T}$ is the vector containing $N$-dimensional gravity anomaly observations and the superscript $T$ stands for transposition. This inverse problem is nonlinear it is solved iteratively by the Nelder and Mead's (1965) simplex method which does not require the differentiability of the objective function with respect to the parameters. We follow the method after Paviani and Himmelblau (1969) for solving nonlinear problems by introducing a tolerance positive decreasing function to the Nelder and Mead (1965) simplex method. The function serves as a tolerance criterion for the constraint violation and also as a termination criterion and the optimization proceeds in similar manner. 

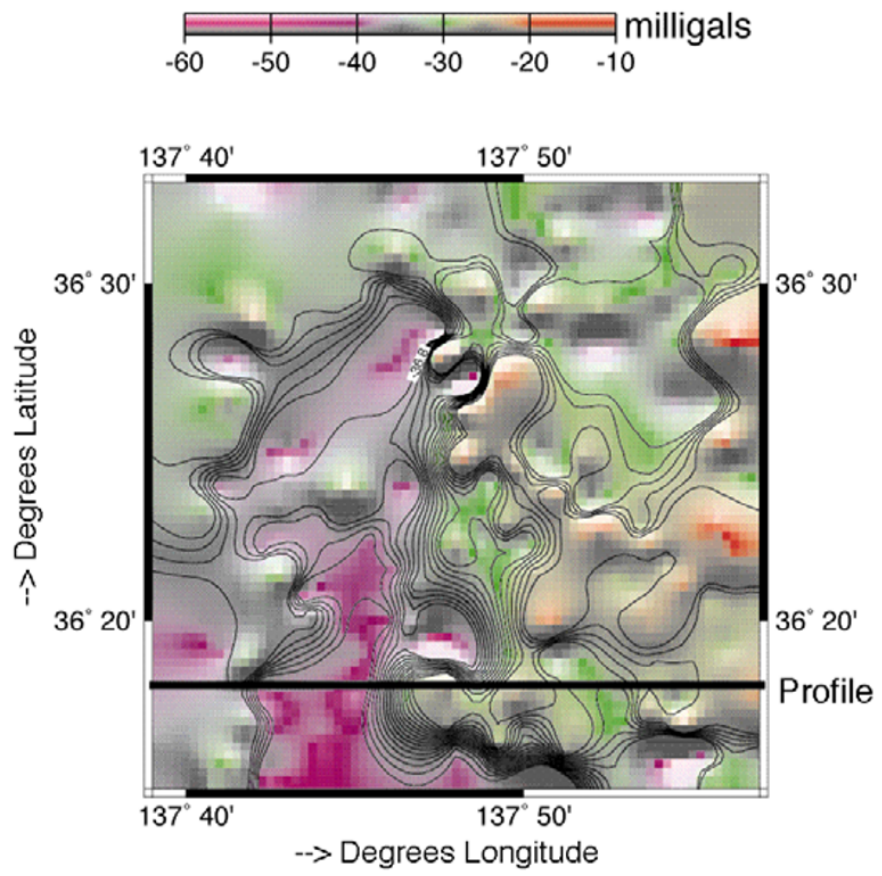

Fig. 2. The Bouguer anomaly ( $2 \mathrm{mGals}$ contour interval) in the vicinity of selected region of the faults and/or tectonic lines at $0.45 \times 0.45 \mathrm{~km}$ regular grid. A line marks the profile across the Bouguer anomaly map at Latitude 36.30 Degrees North.

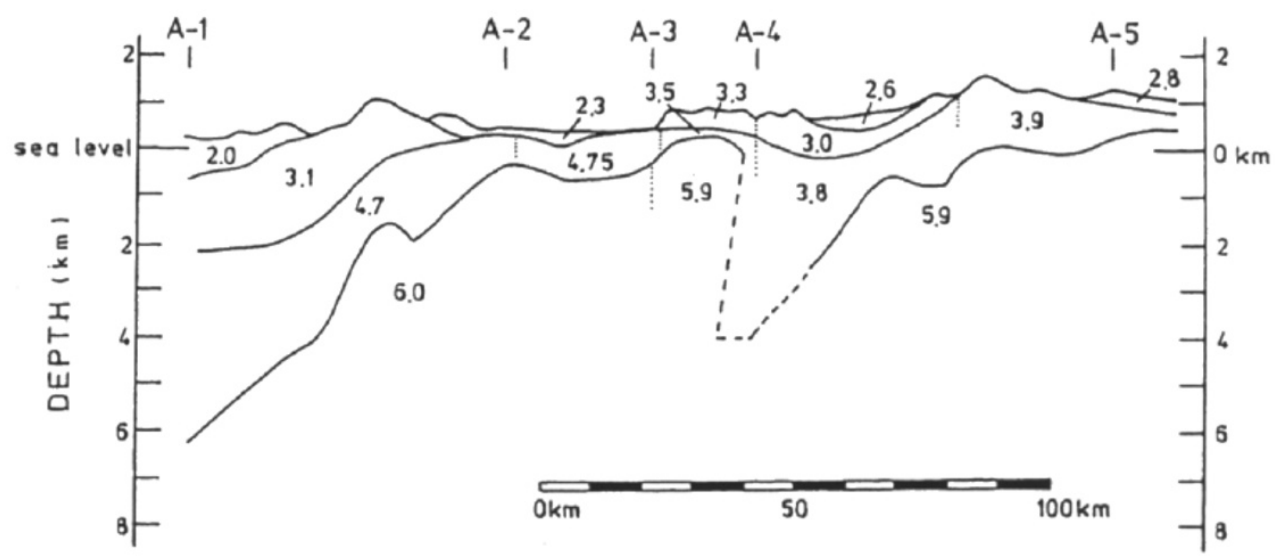

Fig. 3. Crustal structure across the region in NE-SW orientation. The numerals indicate P-wave velocities in $\mathrm{km} / \mathrm{s}$. Vertical dotted line show the location of the velocity boundary while the broken lines show the fault-like structure referred to Bouguer gravity anomaly (Modified after Ikami et al., 1986).

\section{Applications in the Central Ranges, Japan \\ 3.1 Geological background}

The Itoigawa-Shizuoka Tectonic Line (ISTL) - a major fault in Honshu extends from Itoigawa on the coast of Sea of Japan to Shizuoka on the Pacific Coast. It marks the western margin of the Fossa Magna, which is known as the greatest depression in Central Honshu. In the northern area along ISTL, it is recognized that several faults trend from north to south. In Nagano and the Matsumoto basins, alluvial and diluvial deposits are spread widely while the Tertiary sedimentary rocks are partly exposed. Paleozoic and Mesozoic rocks are distributed west of ISTL, that runs North-South at the research area.

The Central Ranges consist of the Hida, Akaishi and Kiso mountain ranges and are bounded by ISTL to the east and the Atera fault (AF) to the southwest across which the regional
Bouguer anomaly pattern changes sharply. The correlation of Bouguer anomaly with topography is strongly negative in the Hida Mountains, marginally in the Akaishi Mountains and significantly positive in the Kiso Mountains. The Central Ranges have uplifted largely through the late Quaternary. The rate of uplifting is $1-3 \mathrm{~mm} /$ year in the Hida Mountains. The uplift in the region has sometimes been discussed in conjunction with the subduction of the Philippine Sea plate along the Nankai trough (Ando, 1975).

The Hida, Akaishi and Kiso mountain ranges accompany the Matsumoto basin (the northern Fossa Magna) and the Kofu basin (the southern Fossa Magna) and the Ina basin on their eastern part. They are characterized by a strongly negative Bouguer anomaly that can be attributed to the thick Tertiary to Quaternary sediments and reaches the maximum in the western periphery of each basin using an average 


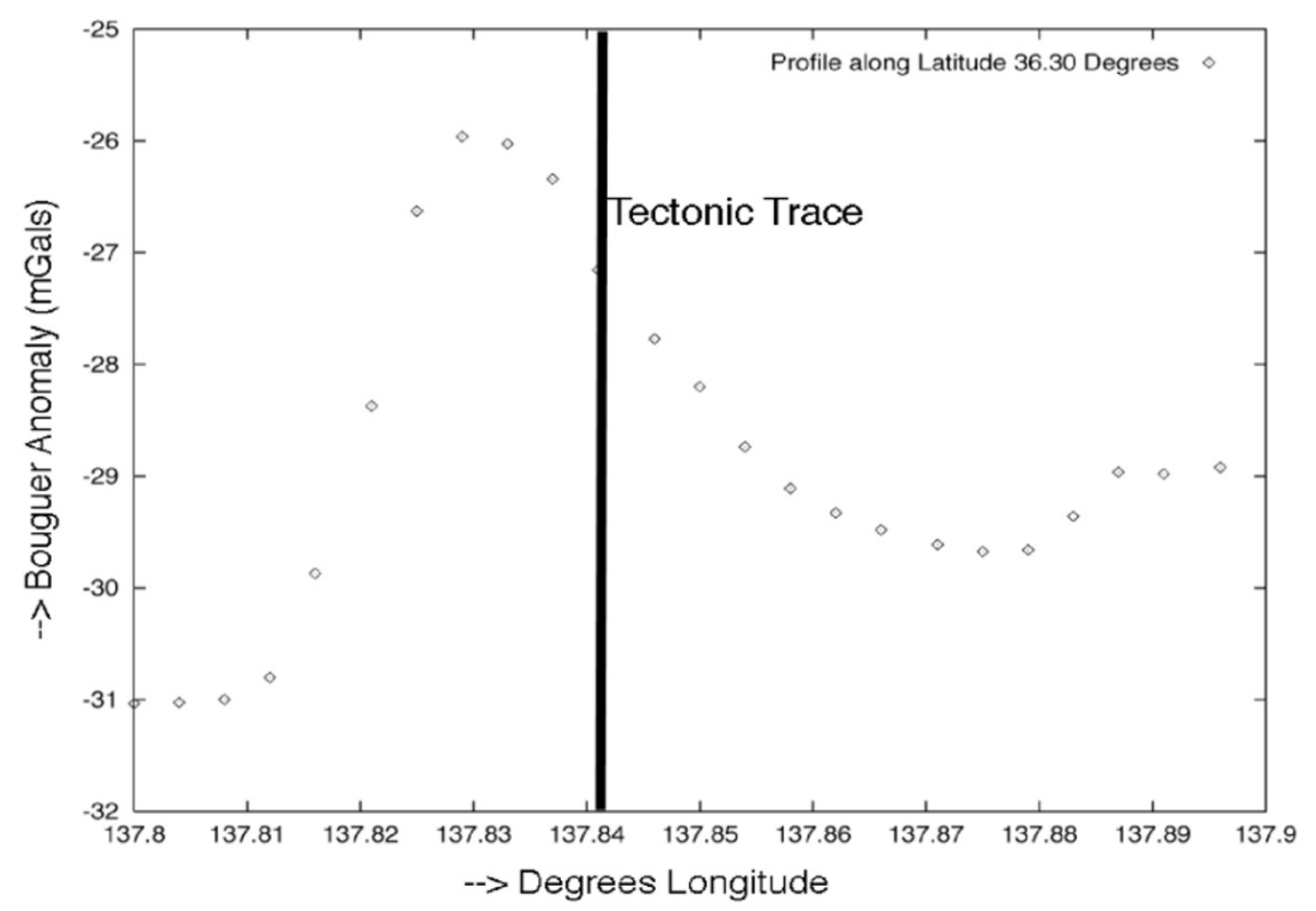

Fig. 4. Gravity anomaly profile along Latitude 36.30 Degrees North showing the location of the ISTL trace and the selected portion of the profile for the inversion analysis.

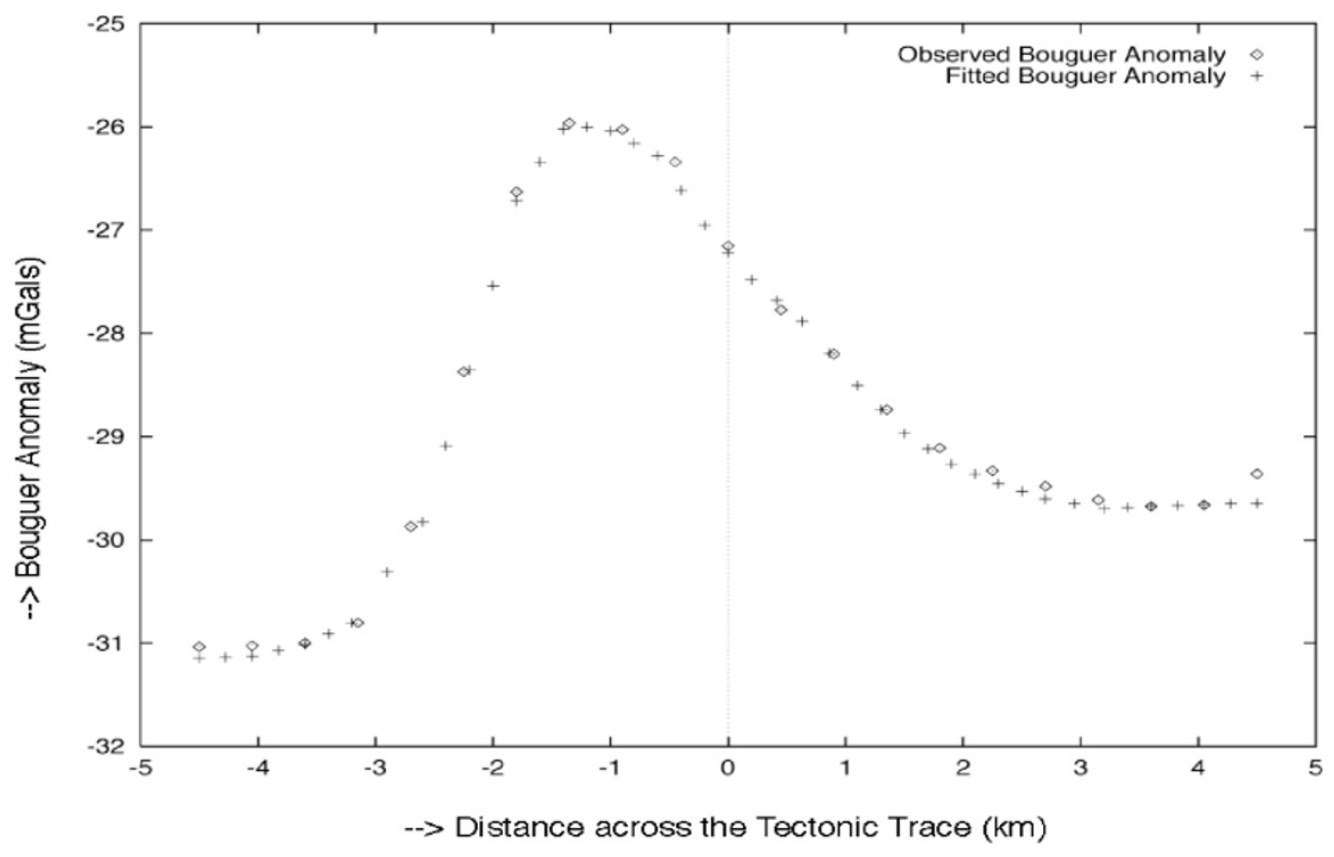

Fig. 5. Observed and fitted Bouguer gravity anomalies across the tectonic/fault line along Latitude 36.30 degrees North.

Bouguer reduction density of $2.64 \mathrm{~g} / \mathrm{cm}^{3}$ (Yamamoto et al., 1982). Further, Yamamoto et al. (1982) gives the geological locations of the tectonic lines in Central Ranges i.e. ISTL, Median Tectonic Line (MTL), Akaishi Tectonic Line (ATL) and AF. Figure 2 shows the complete Bouguer anomaly in vicinity of junction of the ISTL and MTL. In the computations terrain computations to a distance of $22 \mathrm{~km}$ around point station were considered. The outer limit for the terrain computations is $25 \mathrm{~km}$ because the distant topography be- yond $22 \mathrm{~km}$ must be adjusted for the curvature of the Earth and can sometimes produce negative terrain effects (Nowell, 1999). Figure 3 shows the probable crustal structure across the Central Ranges in the NE-SW orientation after Ikami et al. (1986). The tectonic trace is inferred from geologi$\mathrm{cal} / \mathrm{seismic}$ studies in the vicinity. The chosen section for the analysis of Bouguer anomaly profile along Latitude 36.30 Degrees North is shown in Fig. 4 while Fig. 5 shows the observed and fitted Bouguer gravity anomalies of the same. 
Table 2. The initial densities of the sub-surface layers for inclined dike model. $\Delta \rho(z)=-0.515+0.109 z-0.003 z^{2} \mathrm{~g} / \mathrm{cm}^{3}$.

\begin{tabular}{cccc}
\hline Layer & Layer depth $(\mathrm{km})$ & $\begin{array}{c}\text { Density Contrast, } \\
\Delta \rho(z)\left(\mathrm{g} / \mathrm{cm}^{3}\right)\end{array}$ & $\begin{array}{c}\text { Sub-surface depths } \\
(\mathrm{km})\end{array}$ \\
\hline 1 & 0.0 & -0.520 & 0.65 \\
2 & 1.0 & -0.461 & 1.34 \\
3 & 2.0 & -0.358 & 1.81 \\
4 & 3.0 & -0.261 & 2.65 \\
5 & 4.0 & -0.170 & 3.75 \\
6 & 5.0 & -0.085 & 4.23 \\
7 & 6.0 & 0.006 & 4.75 \\
8 & 7.0 & 0.067 & 5.85 \\
\hline
\end{tabular}

\begin{tabular}{lllllll}
\hline & & & & & & \\
-0.53 & -0.43 & -0.33 & -0.23 & -0.13 & -0.03 & 0.07
\end{tabular}

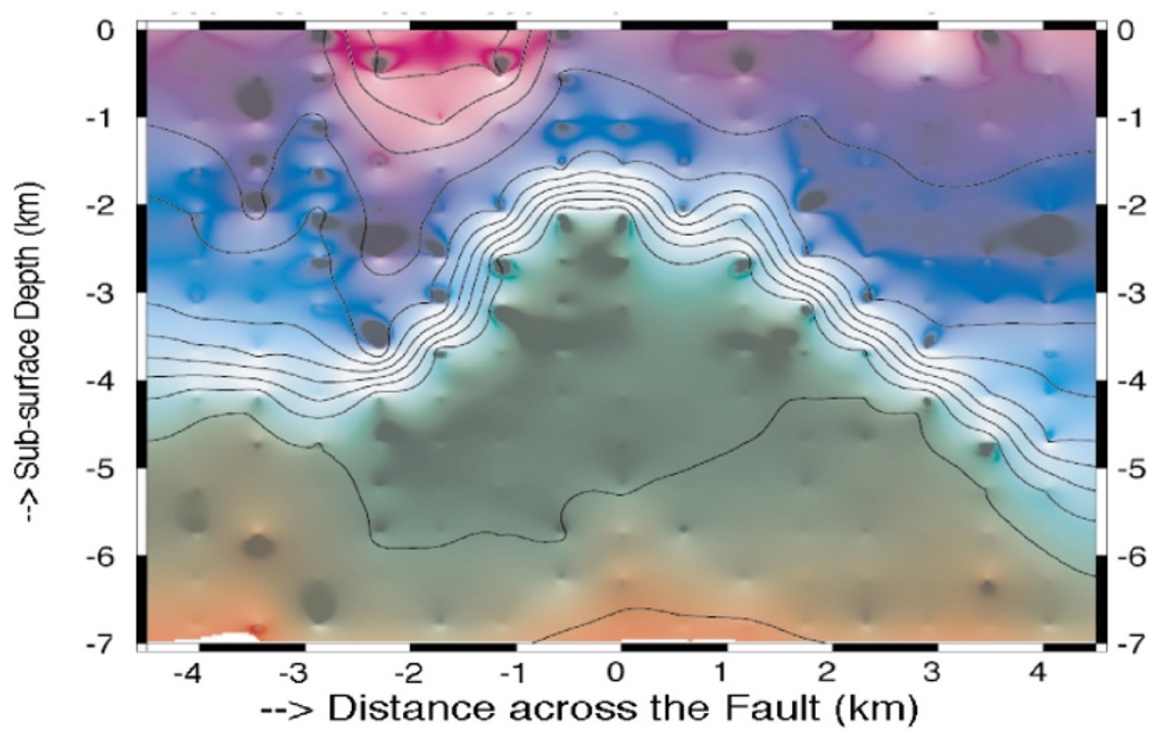

Fig. 6. The probable sub-surface structure (contour interval of $0.05 \mathrm{~g} / \mathrm{cm}^{3}$ ) modeled in the range $x[-4.5 \mathrm{~km}, 4.5 \mathrm{~km}]$ across the ISTL along Latitude 36.30 degrees North.

\subsection{Inversion results}

For the gravity inversion, complete Bouguer anomaly across the ISTL at Latitude 36.30 degrees North was chosen and consisted of equi-spaced values defined in the interval $x$ $[-5 \mathrm{~km}, 5 \mathrm{~km}]$. Since the Bouguer anomalies had been rendered into a grid form - we had gravity anomaly across the tectonic line at regular spacing of about $0.45 \mathrm{~km}$. Various numerical experiments and similar experiments after Telford et al. (1990) show the shape depicted by the Bouguer anomaly across the ISTL at Latitude 36.30 degrees North mimics the shape of the Bouguer anomaly of sub-surface dike-like structure. Subsequently, we applied the gravity inversion modeling on the Bouguer anomaly with possibility of a 2-D dikelike as the causative sub-surface structure.

In the inversion process we utilized absolute proximity and inequality constraints. The absolute proximity constraints imposed some parameter estimates to be as close possible or equal given numerical values within the obser- vation and processing errors. In the test of the inequality constraint, we restricted the estimated density contrasts between model surface $\left(z_{0}\right)$ and a model depth of $7 \mathrm{~km}$ to be between -0.520 and $0.067 \mathrm{~g} / \mathrm{cm}^{3}$ respectively as shown in Table 2.

The resultant parameters of the sub-surface dike were rendered in grid form by GMT (Wessel and Smith, 1995) method to give the result shown in Fig. 6 which shows the probable sub-surface structure across the tectonic line at contour intervals of $0.05 \mathrm{~g} / \mathrm{cm}^{3}$ in the range $x[-4.5 \mathrm{~km}, 4.5 \mathrm{~km}]$. The average terrain height across the tectonic line was about $750 \mathrm{~m}$ above sea level but assumed to be the zero level $\left(z_{0}\right)$ in the model.

\section{Discussions}

Our research shows that the causative sub-surface structure to the Northeast or East of the tectonic trace resembles an intrusive dike-like structure from inversion of the inver- 
sion results. It can be seen by the intrusion into the upper crust of the basement rocks in the vicinity of the tectonic trace. The concentration of contours just below the tectonic suggests the change in density contrasts of the basement rocks is becomes sparse away from the tectonic trace. Earlier geological and geophysical references show the fault near A4 may be identified as the Tsunan-Matsumoto tectonic line, which runs north-westwards (Ikami et al., 1986). Further, the change of structure near ISTL may be gradual and it might not be so sharp, as to be detected by explosion seismic experiments, besides it is impossible to construct the best model with time-term method only (Ikami et al., 1986). The SW of the point A4 (Fig. 3) is marked by an uncertainty as to the shape of the causative structure as the seismic method could not delineate it clearly.

The seismic experiments suggest a thick sedimentary basin to the Southwest or West of A-4. The seismic data analysis for the southern part of the profile indicates that the upper boundary of the basement becomes shallow to the southwest with a slightly folded structure (Ikami et al., 1986). Similar results are obtained in inversion analysis only that the broken-like structure likened in Fig. 3 is not corroborated, though the difference in distance is significantly smaller. In fact, our analysis shows it is likely to be part of the intrusive dike-like structure present towards the Northeastern or Eastern part of the tectonic trace.

\section{Conclusions}

We conclude that a relatively shallow intrusion of a dikelike structure into the upper layers is responsible for Bouguer anomaly high depicted to the Northeast or East of the tectonic trace. While the Bouguer gravity low anomaly to the Southwest or West of the tectonic trace is due to lower density sedimentary rocks thrust lower into the higher density crust to a depth range of about $3.5 \sim 4.0 \mathrm{~km}$ below the Earth surface. It is to be noted without reasonable constraints on the model parameters, there can be a wide variety of density models that explain the gravity anomaly as the density contrast function of depth is a relationship that can be an average of a broad region. Locally, the density contrasts of sediments can deviate significantly from such a simple rend. Thus, there is a possibility to utilize as excess density-depth function in the inversion that deviates from the actual condition.

Finally, larger features produce Bouguer gravity anomaly that are smooth over considerable distances referred to as regionals. While localized sources account for sharper anomalies, which if the regionals are removed, can effectively take into account or show effects of the local sub-surface causative structure prominently. Faults also cut several beds and it is only in the unusual instance that the anomaly is due primarily to a single bed of uniform density. Besides, a fault is never a single plane interface of constant dip with displacement only.

Acknowledgments. We would like to express our heartfelt gratitude to the Geological Society of Japan for the entire gravity data utilized in the research as provided on the Gravity CD-ROM of Japan dated 24th March 2000.

\section{References}

Ando, M., Possibility of a major earthquake in the Tokai District, Japan and its pre-estimated seismo-tectonic effects, Tectonophys., 25, 69-85, 1975.

Barbosa, V. C. F., J. B. C. Silva, and W. E. Medeiros, Gravity inversion of basement relief using approximate equality constraints on depths, Geophysics, 62, 1745-1757, 1997.

Blakely, R. J., Potential theory in gravity and magnetic applications, The Cambridge University Press, 1996.

Burger, H. R., Exploration Geophysics of the Shallow Subsurface, Prentice Hall, Englewood Cliffs, New Jersey 07632, 1992.

Butler, D. K., Generalized gravity gradient inversion for 2-D inversion, Geophysics, 60(4), 1018-1028, 1995.

Geldart, L. P., E. D. Gill, and B. Sharma, Gravity anomalies of twodimensional faults, Geophysics, 31(2), 372-397, 1966.

Hirokawa, O., Geological Map of Japan, 1:1,000,000 (2nd Edition), Geological Survey of Japan, 1978.

Ikami, A., T. Yoshii, S. Kubota, Y. Sasaki, A. Hasemi, T. Moriya, H. Miyamachi, R. S. Matsu'ura, and K. Wada, A Seismic-refraction Profile in and around Nagano Prefecture, Central Japan, J. Phys. Earth, 34, 457474, 1986

Medeiros, W. E. and J. B. C. Silva, Geophysical inversion using approximate equality constraints, Geophysics, 61, 1678-1688, 1996.

Nelder, J. A. and R. Mead, A simplex method for function minimization, Computer J., 7, 308-313, 1965.

Nowell, D. A. G., Gravity terrain corrections-An Overview, J. Appl. Geophys., 42, 117-134, 1999.

Parasnis, D. S., Principles of Applied Geophysics, Chapman \& Hall, 1997.

Parker, R. L., Best bounds on density and depth from gravity data, Geophysics, 34, 315-334, 1974.

Paviani, M. R. and D. M. Himmelblau, Constrained nonlinear optimization by Heuristic Programming, Journal of Operations Research Society of America (ORSA), 17, 872, 1969.

Rao, D. B., Modeling of sedimentary basins from gravity anomalies with variable density contrast, Geophys. J. Roy. Australian Soc., 84, 207-212, 1986.

Telford, W. M., L. P. Geldart, and R. E. Sheriff, Applied Geophysics. 2nd Edition, Cambridge University Press, New York, 1990.

Wessel, P. and W. H. F. Smith, The Generic Mapping Tools (GMT) Version 3.0 Technical Reference and Cookbook, SOEST/NOAA, 1995.

Yamamoto, A., K. Nozaki, Y. Fukao, H. Furumoto, R. Shichi, and T. Ezaka, Gravity survey in the Central Ranges, Honshu Japan, J. Phys. Earth, 30, 201-243, 1982.

Zhang, J., B. Zhong, X. Zhou, and Y. Dai, Gravity anomalies of 2-D bodies with variable density contrast, Geophysics, 66(3), 809-813, 2001.

I. L. Ateya (e-mail: ateya@kugi.kyoto-u.ac.jp) and S. Takemoto 